\title{
A New Route to Process Diamond Wires
}

\author{
Marcello Filgueira $^{\mathrm{a} *}$, Guerold Bobrovnitchii ${ }^{\mathrm{a}}$, Daltro Garcia Pinatti ${ }^{\mathrm{b}}$ \\ ${ }^{a}$ Universidade Estadual do Norte Fluminense, Laboratório de Materiais Avançados, \\ Av. Alberto Lamego, 2000, 28015-620 Campos dos Goytacazes - RJ, Brasil. \\ ${ }^{\mathrm{b}}$ Departamento de Engenharia de Materiais DEMAR/FAENQUIL, \\ Polo Urbo Industrial, Gleba AI6, 12600-000 Lorena - SP, Brazil
}

Received: October 7, 2002; Revised: December 8, 2002

\begin{abstract}
We propose an original route to process diamond wires, denominated In Situ Technology, whose fabrication involves mechanical conformation processes, such as rotary forging, copper tubes restacking, and thermal treatments, such as sintering and recrystallisation of a bronze 4 wt.\% diamond composite. Tensile tests were performed, reaching an ultimate tensile strength (UTS) of $230 \mathrm{MPa}$ for the diameter of $\varnothing=1.84 \mathrm{~mm}$. Scanning electron microscopy showed the diamond crystals distribution along the composite rope during its manufacture, as well as the diamond adhesion to the bronze matrix. Cutting tests were carried out with the processed wire, showing a probable performance 4 times higher than the diamond sawing discs, however its probable performance was about 5 to 8 times less than the conventional diamond wires (pearl system) due to the low abrasion resistance of the bronze matrix, and low adhesion between the pair bronzediamond due to the use of not metallised diamond single crystals.
\end{abstract}

Keywords: diamond wires, In Situ Technology, swaging, sintering.

\section{Introduction}

Diamond wires are cutting tools for rocks (marble, granite etc.), concrete and substitutes of saws in general ${ }^{1-5}$. They are composed of an AISI 316 stainless steel cable over which are assembled diamond sintered pearls with 10 to $12 \mathrm{~mm}$ in diameter spaced $25 \mathrm{~mm}$ between each one. The slabbing operation is carried out with a driven pulley coupled to a motor which promotes the diamond wire rotation. The wire is passed through coplanar holes previously made in the rock, and the tension imposed to the wire is made by a motor mounted on trails, coupled to the cutting system. The utilization of this slabbing technology has been expanded all over the world due to its advantages on the other techniques.

Linear and circular saws, grinding wheels, wire saw pearls among others, are diamond cutting tools used in the slabbing, cutting, and polishing of dimension stones, ceramic materials and nonferrous metals in general ${ }^{6}$. There are a wide range of types of materials used in the manufacture of these tools, but the most employed is the system metal bond

*e-mail: marcello@uenf.br

Trabalho apresentado no $1^{\circ}$ Congresso da Sociedade Brasileira em Materiais, Rio de Janeiro, Julho de 2002. matrix-diamond crystals ${ }^{7}$. Diamonds are impregnated in the metal matrix via two ways: electrodeposition or sintering. In the electrodeposited tools there are only a monolayer of diamonds on the tool surface, while the sintered ones show diamond crystals distributed into the bulk and on the surface of the tools, and is cheaper and easier to process. In this sense, sintered diamond cutting tools are more usual ${ }^{7,8}$.

The metal matrix selection is based on the abrasivity of the material to be cut or polished. For highly abrasive materials such as concrete, $\mathrm{SiC}, \mathrm{Si}_{3} \mathrm{~N}_{4}, \mathrm{Al}_{2} \mathrm{O}_{3}$, tungsten bond is used. Cobalt bond is employed in the cutting of materials whose abrasivities are similar to the granites. Bronze, cobalt bonds and its alloys are used for marbles. Brass, bronze or copper bonds are employed in the cutting of ceramics, glasses, and nonferrous metals ${ }^{7}$.

The sintering is normally accomplished by hot pressing. In this case, the powder or green body (in the desired form) is submited to sintering at the same time in which it is pressed into a mold. A classical example is performed by Contardi ${ }^{9}$, explaining a method to process diamond pearls for cutting 
wires, where the metal matrix bond + diamond crystals mix is confined into holes of a graphite mold. This mold is put into a resistive vacuum furnace chamber coupled to a press. The press punches conduct the current for the green bodies sintering, at the same time that press them into the mold holes. The productivity is high, about 960 pearls per $8 \mathrm{~h}$.

In this work we present an alternative route to process diamond composites, denominated In Situ Technology, which involves conventional sintering and swaging (rotary forging) of the metal matrix-diamond mix, instead of the conventional hot pressing route. It was produced wires of bronze $4 \mathrm{wt} . \%$ diamond for use as diamond wires and linear saws in general. Table 1 gives the comparison of geometric data of diamond wires fabricated by pearls and in situ techniques. Diamond volume and surface in the in situ wire are 20 to 30 times larger than pearls wire, and cutting section of rocks are decreased to $40 \%{ }^{10}$.

\section{Experimental}

Table 2 shows the typical concentration vs. density of diamond in cutting tools. In the present work we used a concentration $50\left(2.2 \mathrm{carat} / \mathrm{cm}^{3} ; 0.44 \mathrm{~g} / \mathrm{cm}^{3} ; 0.1264 \mathrm{~cm}^{3}\right.$ of dia$\mathrm{mond} / \mathrm{cm}^{3}$ of tool) since this is the concentration used to cut dimension stones. Figure 1 shows the processing flow chart of the bronze/diamond cap, starting with bronze $4 \mathrm{wt} . \%$ dia-

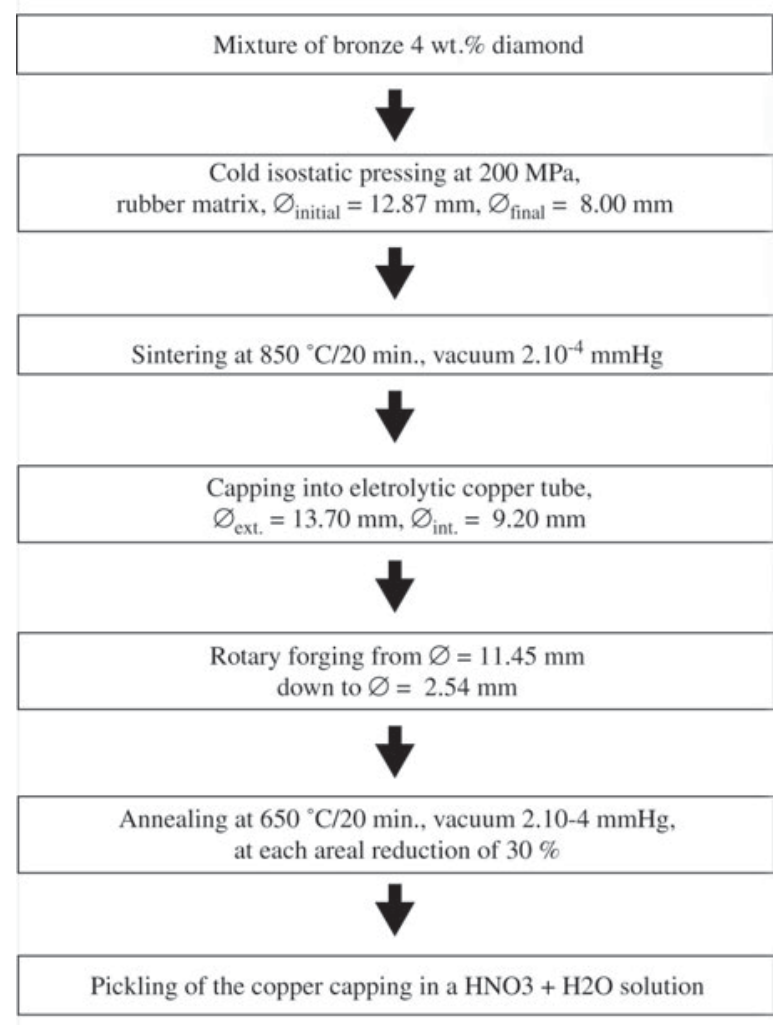

Figure 1. Processing flow chart of the bronze / diamond external cap.

Table 1. Comparative geometric data between pearls and in situ diamond wire.

\begin{tabular}{lccc}
\hline Data & Pearls & \multicolumn{2}{c}{ In Situ } \\
\hline$\phi_{\mathrm{e}}$ (external diameter) & $10 \mathrm{~mm}$ & $8 \mathrm{~mm}$ & $6 \mathrm{~mm}$ \\
$\phi_{\mathrm{i}}$ (internal diameter) & $7 \mathrm{~mm}$ & $5 \mathrm{~mm}$ & $3 \mathrm{~mm}$ \\
Width & $5 \mathrm{~mm}($ pearls $)$ & \multicolumn{2}{c}{$1000 \mathrm{~mm}$ (length/m) } \\
Spacing & $25 \mathrm{~mm}$ & Continuous & \\
Diamond volume/m & & $30.630 \mathrm{~mm}^{3}$ & $21.206 \mathrm{~mm}^{3}$ \\
Diamond surface $/ \mathrm{m}^{+}$ & $1000 \mathrm{~mm}^{3}$ & $25.133 \mathrm{~mm}^{3}$ & $18.850 \mathrm{~mm}^{3}$ \\
\hline Relation between in situ/pearls & $785 \mathrm{~mm}^{3}$ & 30 & 21 \\
& Volume & 32 & 24 \\
\hline
\end{tabular}

*Diamond volume $/ \mathrm{m}: \pi / 4 \times\left(\phi_{\mathrm{e}}^{2}-\phi_{\mathrm{i}}^{2}\right) \times$ width $\times$ number of pearls $/ \mathrm{m} ;{ }^{+}$Diamond surface $/ \mathrm{m}: \pi \times \phi_{\mathrm{e}} \times$ width $\times$ number of pearls $/ \mathrm{m}$.

Table 2. Typical concentration versus density of diamonds in cutting tools.

\begin{tabular}{|c|c|c|c|}
\hline \multirow[t]{2}{*}{ Concentration of diamond } & \multicolumn{2}{|c|}{ Mass of diamond $/ \mathrm{cm}^{3}$ of tool volume } & \multirow{2}{*}{$\begin{array}{l}\text { Volume of diamond } \\
\left(\mathrm{cm}^{3}\right) / \text { tools }\left(\mathrm{cm}^{3}\right)\end{array}$} \\
\hline & Carat & Grams & \\
\hline 150 & 6.60 & 1.32 & 0.38 \\
\hline 125 & 5.50 & 1.10 & 0.32 \\
\hline $100 *$ & 4.40 & 0.88 & 0.25 \\
\hline 75 & 3.30 & 0.66 & 0.19 \\
\hline 50 & 2.20 & 0.44 & 0.13 \\
\hline 42 & 1.85 & 0.37 & 0.11 \\
\hline 30 & 1.32 & 0.26 & 0.07 \\
\hline 25 & 1.10 & 0.22 & 0.06 \\
\hline
\end{tabular}

* Concentration 100 refers to $25 \%$ in tool volume of diamond per $\mathrm{cm}^{3}$ of tool and has 4.4 carat of diamond $/ \mathrm{cm}^{3}$ of tools; $1 \mathrm{carat}=0.2 \mathrm{~g}$. The fourth column is obtained by dividing the third column by the diamond density $\left(\rho_{\text {diam. }}=3.48 \mathrm{~g} / \mathrm{cm}^{3}\right)$. 
mond. The materials used in this work are: De Beers SDA + 65 40/50 mesh diamonds, commercial atomised copper powder $(75 / 60 \mathrm{~mm})$, and OFHC copper tubes.

\section{Results and Discussion}

Microstructural and tensile behaviour

Figure $2 \mathrm{a}$ shows the longitudinal microstructure of the initial sintered bronze $4 \mathrm{wt}$. $\%$ diamond at $\varnothing=8.00 \mathrm{~mm}$. The diamond distribution is relatively spaced. Samples were cupped in backelite and ground by 80 mesh emery paper.
$1 \mathrm{H}_{2} \mathrm{O}+1 \mathrm{HNO}_{3}$ picking did not work because corrosion was not uniform and pitting tooke place in the bronze/diamond interface. Figure $2 \mathrm{~b}$ shows the cross section of the diamond wire at $\varnothing=1.84 \mathrm{~mm}(\mathrm{R}=18.90 \mathrm{X})$. It can be observed that during the wire area reduction by swaging the diamond crystals keeps their physical integrity. This result is of great importance because it gives viability to the in situ processing route, never used before. For bronze 4 wt.\% diamond, the rupture load is shown as a function of the external cap diameter along the various stages of the processing (Fig. 3a). The curve of Fig. 3a does not extrapolate to zero, but to
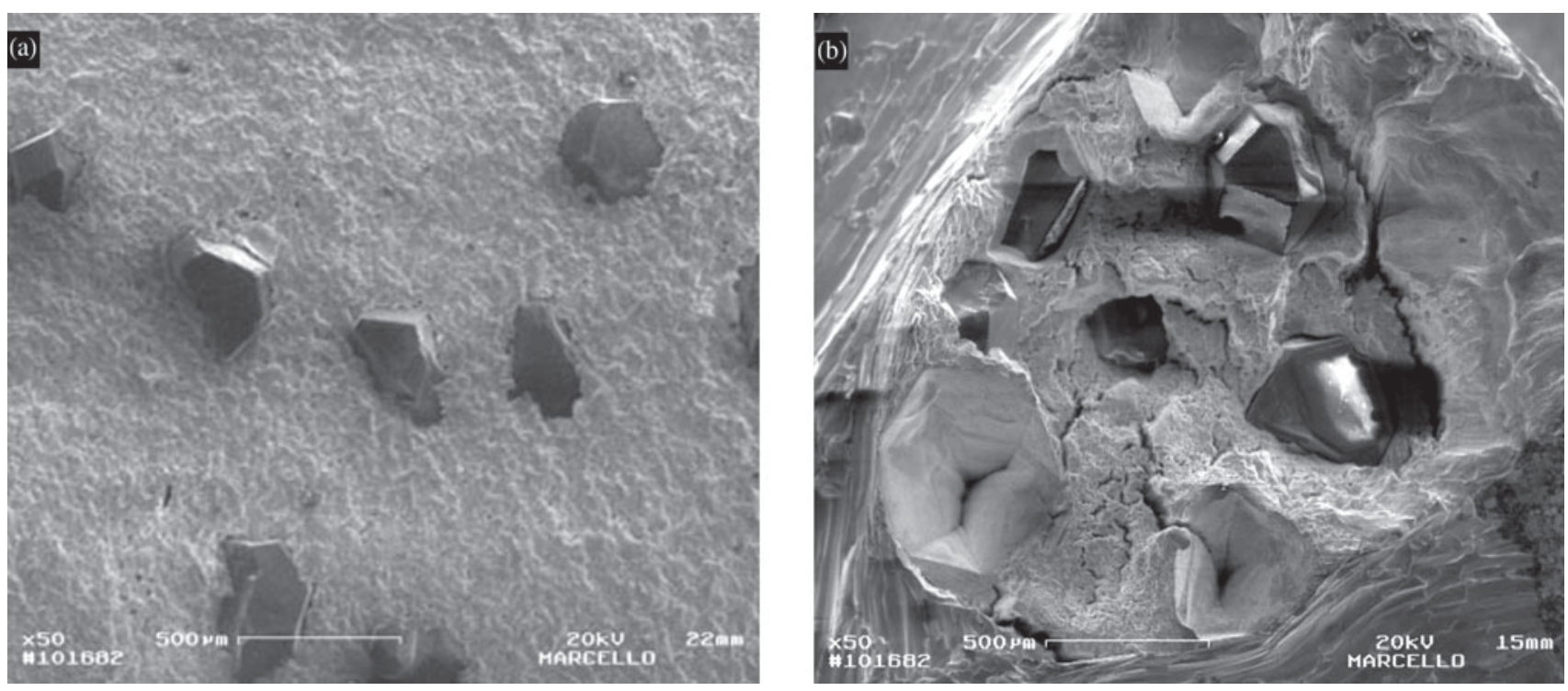

Figure 2. (a)Longitudinal section of the sintered bronze 4 wt. $\%$ diamond, $\varnothing=8.00 \mathrm{~mm}$, and (b) cross section of diamond composite, $\varnothing=1.84 \mathrm{~mm}$
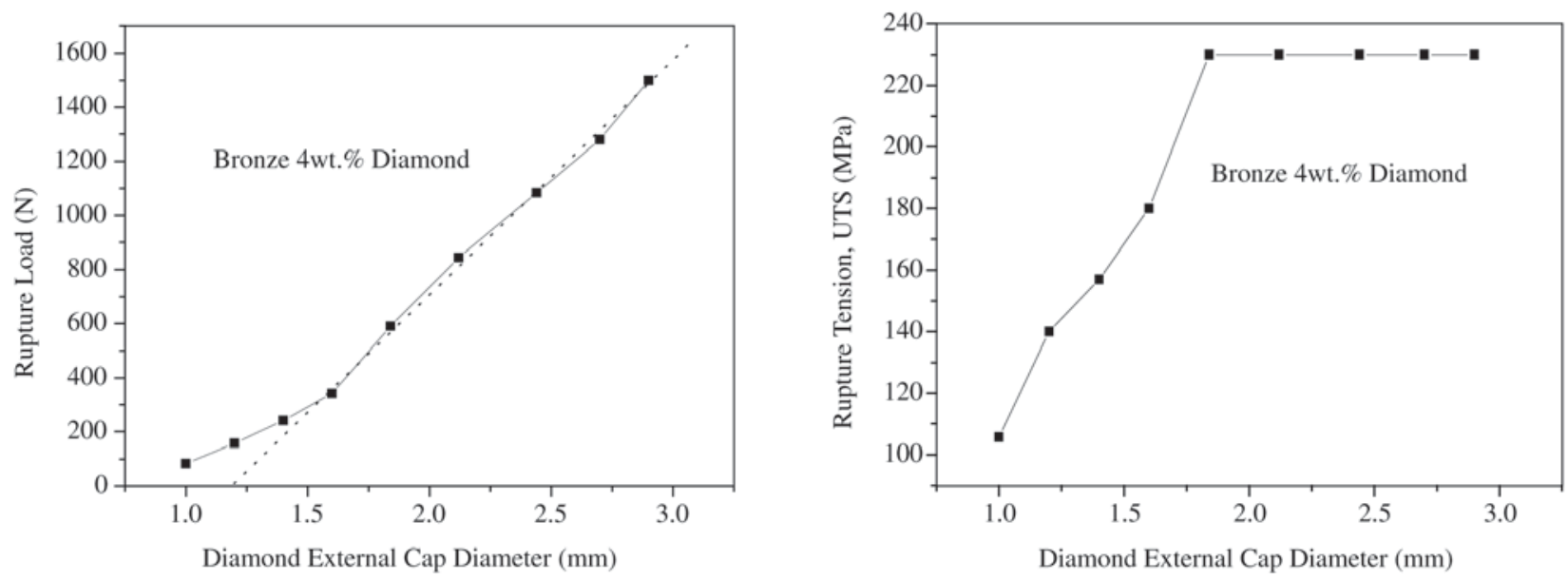

Figure 3. (a)Rupture load $(\mathrm{N})$ as a function of diamond external cap diameter (mm), and (b) rupture tension (UTS) as a function of diamond external cap diameter ( $\mathrm{mm})$. 

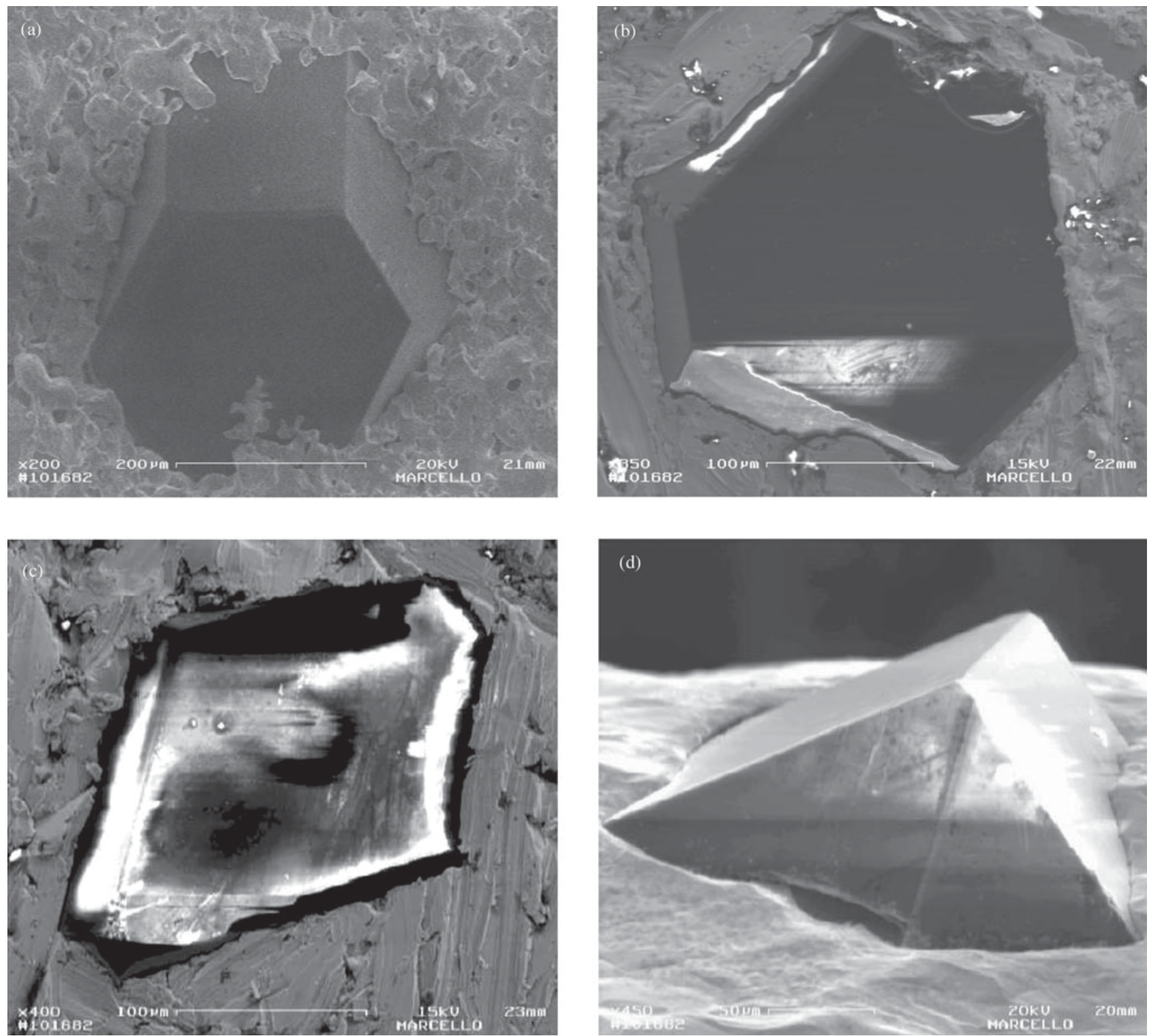

Figure 4. (a) View of a diamond crystal spyked in the bronze matrix. Sample as sintered. (b)Bronze-diamond interface. $\varnothing=5.00 \mathrm{~mm}$, Longitudinal view. (c) Bronze - diamond interface, $\varnothing=3.30 \mathrm{~mm}$, longitudinal view. (d) Bronze - diamond interface, $\varnothing=1.84 \mathrm{~mm}$, longitudinal view.

$\varnothing=1.20 \mathrm{~mm}$ (extrapolation of the dashed line), and this diameter is the limit of the contact diamond to diamond. With it, the rupture load is $180 \mathrm{~N}$, indicating an adherence between bronze and diamond of $160 \mathrm{MPa}\left(\sigma \approx 180 \mathrm{~N} /\left[\pi . \varnothing^{2} / 4\right] \approx 180\right.$ $\left.\mathrm{N} /\left[(\pi / 4) \cdot(1 \cdot 20)^{2} \cdot 10^{-6} \mathrm{~m}^{2}\right] \approx 160 \mathrm{MPa}\right)$. In Fig. $3 \mathrm{~b}$ the UTS remains constant at $230 \mathrm{MPa}$ for diameters up to $\varnothing=1.84 \mathrm{~mm}$, after which it decreases. The data of Fig. $3 \mathrm{~b}$ refers to the UTS values for the same material, indicating that $\varnothing=1.84 \mathrm{~mm}$ is the optimum diameter for this composition and mean crystal diamonds size of $350 \mu \mathrm{m}$.
Measurements are made in the annealed condition $\left(650^{\circ} \mathrm{C} / 20 \mathrm{~min}\right)$ and data are an average over 5 to 7 samples. The experimental average modulus of elasticity is $\mathrm{E}=11.5 \mathrm{GPa}$, but for annealed commercial bronze, $\mathrm{UTS}=260 \mathrm{MPa}$ and $\mathrm{E}=16 \mathrm{Gpa}^{8,9}$. The presence of diamond up to $\varnothing=1.84 \mathrm{~mm}$ has minor influence in UTS, but it decreases $\mathrm{E}$ (more flexible material) since it is now distributed as a composite. Conventional diamond wire has a rupture load between 1200 and $3000 \mathrm{~N}$ (UTS $=60$ and $150 \mathrm{MPa}$, considering $\varnothing=5.00 \mathrm{~mm}$ for the AISI 316 core). 
The bronze $4 \mathrm{wt} . \%$ diamond at $\varnothing=1.84 \mathrm{~mm}$ has a rupture load of $611 \mathrm{~N}$ (230 MPa), higher than the AISI 316 core. All the tensile tests are performed according to the Ref. 11.

\section{Bronze - Diamond Adherence}

Figure 4 show the interface bronze-diamond in the various stages of the processing (as sintered $\varnothing=8.00 \mathrm{~mm}$, $\varnothing=5.00 \mathrm{~mm}, \phi=3.30 \mathrm{~mm}$, and $\phi=1.84 \mathrm{~mm})$. The $\mathrm{Cu}$ layer is removed with $1 \mathrm{H}_{2} \mathrm{O}+\mathrm{HNO}_{3}$ in order to expose the diamond cutting faces. There are no gaps (faults) between bronze and diamond. There is no interdiffusion between them, and the adherence is smaller than the UTS $=230 \mathrm{MPa}$ of the bronze $4 \mathrm{wt} \%$ diamond.

\section{Preliminary cutting of marble}

Table 3 presents the data of marble cutting by means of a
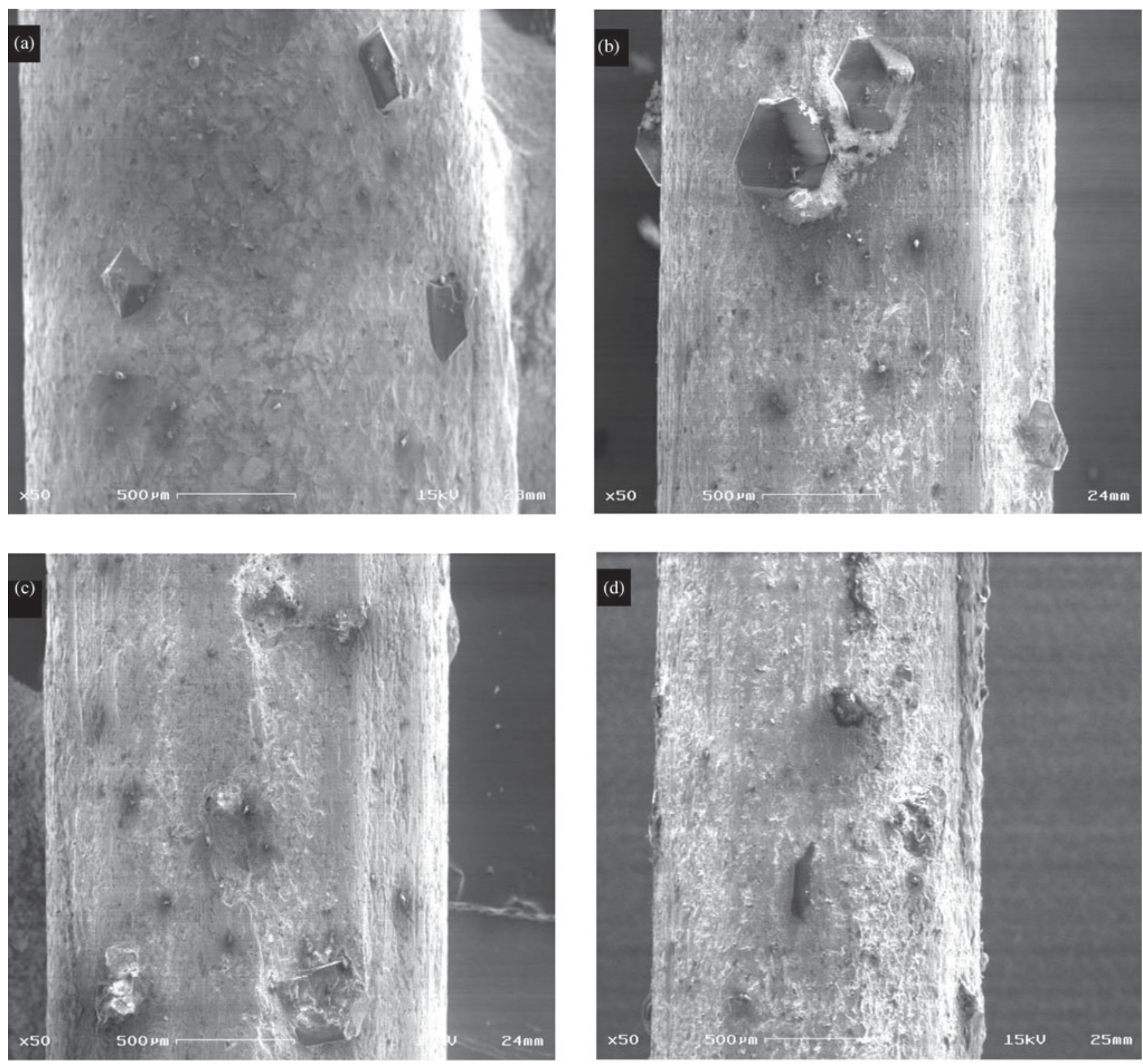

Figure 5. Marble cutting of in situ wire. (a)Before cutting operation, $\phi=1.93 \mathrm{~mm}$. (b)After cutting an area of $\mathrm{A}=605 \mathrm{~cm}^{2}, \phi=1.61 \mathrm{~mm}$. (c) After cutting an area of $\mathrm{A}=1180 \mathrm{~cm}^{2}, \phi=1.23 \mathrm{~mm}$. (d) Silver welded junction of in situ diamond wire. 
Table 3. Marble cutting data with the in situ diamond wire.

\begin{tabular}{lcccc}
\hline $\mathrm{N}$ & $\phi(\mathrm{mm})$ & $\sigma(\mathrm{mm})$ & $\pm \varepsilon(\mathrm{mm})$ & $\mathrm{A}\left(\mathrm{cm}^{2}\right)$ \\
\hline 6 & 1.93 & 0.06 & 0.02 & 0.00 \\
10 & 1.79 & 0.06 & 0.02 & 52.50 \\
11 & 1.78 & 0.06 & 0.02 & 65.00 \\
20 & 1.73 & 0.06 & 0.01 & 70.50 \\
22 & 1.69 & 0.04 & 0.01 & 84.00 \\
27 & 1.67 & 0.05 & 0.01 & 104.00 \\
31 & 1.67 & 0.06 & 0.01 & 110.00 \\
31 & 1.61 & 0.06 & 0.01 & 119.00 \\
31 & 1.58 & 0.06 & 0.01 & 118.50 \\
26 & 1.50 & 0.08 & 0.01 & 126.00 \\
34 & 1.44 & 0.10 & 0.02 & 97.50 \\
33 & 1.38 & 0.11 & 0.02 & 101.25 \\
28 & 1.31 & 0.14 & 0.03 & 84.00 \\
18 & 1.23 & 0.12 & 0.03 & 56.25 \\
\hline
\end{tabular}

Number of measurements $\phi$ during cutting: $\mathrm{N}$

$$
\text { Error: } \varepsilon=\frac{\sigma}{(\mathrm{N})^{1 / 2}} \quad \begin{aligned}
& \text { Average diameter: } \begin{array}{l}
\phi \\
\text { Variance: }
\end{array} \\
& \sigma=\frac{\left(\sum\left[\phi_{\mathrm{i}}\right) / \mathrm{N}\right.}{\left.(\mathrm{N}-1]^{1 / 2}\right)^{1 / 2}}
\end{aligned}
$$

monolithic bronze 4 wt.\% diamond wire. Figures 5a, b and c show micrographs of the wire before, in the middle and in the end of the cutting trial, respectively, being made in a linear saw frame of $0.22 \mathrm{~m}$ in length, resulting in $1188 \times 10^{-4} \mathrm{~m}^{3} / 0.22 \mathrm{~m}=0.54 \mathrm{~m}^{2} / \mathrm{m}$ of cut area per meter of wire. In considering that, the braided wires will have 12 bronze $4 \mathrm{wt} . \%$ diamond wires, and we expect a cutting area capacity of $6.5 \mathrm{~m}^{2} / \mathrm{m}$, it corresponds to $5\left(30 \mathrm{~m}^{2} / \mathrm{m}\right)$ to $8\left(50 \mathrm{~m}^{2} / \mathrm{m}\right)$ times less than the pearls-diamond wire. The reason for this poor performance is the low abrasion resistance of the bronze material shown in Fig. 5, where abrasion of the loose diamond powder is clearly seen. Another comparison can be done with results of reference ${ }^{12}$ for granite cutting with a circular saw of $\phi=0.7 \mathrm{~mm}$ with a diamond volume of $\mathrm{V}=1.7 \times 10^{-5} \mathrm{~m}^{3}$ and $\mathrm{a}$ perimeter of $\lambda=1.7 \mathrm{~mm}\left(\mathrm{~V}=10^{-5} \mathrm{~m}^{3} / \mathrm{m}\right.$, effective diamond DAS 100,40/50 mesh and concentration 30). The measured cutting capacity of the circular saw was $0.62 \mathrm{~m}^{2}$ resulting in $0.62 / 1.7=0.35 \mathrm{~m}^{2} / \mathrm{m}$. For marble, the cutting capacity is the double $\left(0.73 \mathrm{~m}^{2} / \mathrm{m}\right)$. The cutting capacity of in situ linear saw frame $\left(0.54 \mathrm{~m}^{2} / \mathrm{m}\right.$ for diamond volume of $\left.\mathrm{v}=1.7 \times 10^{-6} \mathrm{~m}^{3}\right)$ is 4.4 times higher than the Ref. 12 results $\left[\left(0.54 / 1.7 \times 10^{-6}\right)\right.$ : $\left.\left(0.73 / 10^{-5}\right)\right]$. In the sequence of development, it will be used $\mathrm{W}, \mathrm{Co}, \mathrm{W}-\mathrm{Co}$ alloy, Fe or Fe-Co alloy to improve abrasion resistance. It is recognized that the critical point is the adhesion between the diamond and the matrix. Metal coated diamond will also improve the cutting area capacity of the in situ wire.

One of the new feature of the in situ diamond wire is its possibility to be welded after rupture. Fig. 5.d shows the mi- crograph of a silver welded part of the in situ monolithic wire $(\phi=1.69 \mathrm{~mm})$. Mechanical resistance is maintained (UTS = $226 \mathrm{MPa}$ ) in the welded area and diamond of that region is not lost. This characteristic is a considerable improvement over the pearl-diamond wire that is completely lost after rupture.

\section{Conclusions}

A diamond wire was obtained by an alternative route called in situ process by swaging and sintering with maintenance of diamond crystal integrity. By means of this route it is possible to decrease the diameter of the wire from 10 to $6 \mathrm{~mm}$, decreasing then three times the section of the rock to be cut.

Abrasion of the bronze matrix was too high indicating the need of development into two directions: use of metal coated diamond in order to improve adhesion and use of another metal matrix, such as W-Co, or Fe-Co alloys.

For the bronze $4 \mathrm{wt} \%$ diamond rope, with $\phi=1.65 \mathrm{~mm}$ diameter, the UTS $=170 \mathrm{MPa}$ fulfils the requirements of tensile strength to operate as a diamond wire cutting rope.

Adherence between the pair bronze-diamond was weak, due to the fact that the diamonds crystals used in this work were free of metallisation.

The function of silver welding was satisfactory after rupture, promoting the constant recycling of the external cutting rope.

When comparing the cutting data in marble using the in situ external rope, its probable performance was about 4 times higher than the conventional sawing discs, but 5 to 8 times less than the conventional pearl system diamond wires, due to the low abrasion resistance of the bronze matrix and weak adherence between bronze-diamond.

\section{Acknowledgements}

The authors thanks to DEMAR/FAENQUIL for the equipments used in the experiments.

\section{References}

1. Thoreau, B. Diamond Impregnated Wire for Sawing Hard Abrasive Stones. Industrial Diamond Review. v. 2, p. 9495, 1984.

2. Daniel, P. More Granites Succumb to Diamond Wire. Industrial Diamond Review. n. 5, p. 187-194, 1986.

3. Daniel, P. Granite Quarrying - Cut Waste \& Costs. Industrial Diamond Review. n. 1, p. 1-4, 1986.

4. Daniel, P. Slate Without Waste. Industrial Diamond Review. n. 4, p. 200-203, 1993.

5. Pinzari, M. Quarrying Stone by Diamond Wire in Italy. Industrial Diamond Review. v.5, p. 231-336, 1989.

6. Filgueira, M.; Pinatti, D.G. Production of Diamond Wire by $\mathrm{Cu} 15 \% \mathrm{v} \mathrm{Nb}$ in situ Process. Proceedings of the $15^{\text {th }}$ International Plansee Seminar, Reutte/Austria, Plansee Hold- 
ing AG, v. 1, p. 360-374, 2001.

7. Przyklenk, K. Diamond Impregnated tools - Uses and Production. Toolmaking, Industrial Diamond Review, v. 4, p. 192-195, 1993.

8. Filgueira, M. Production of in situ Diamond Wires. PhD. Thesis, State University of North Fluminense, p. 1-153, 2000. (in portuguese)

9. Contardi, G.L. Wire Beads - Economic Productions. Tool- making, Industrial Diamond Review, v. 5, p. 256, 1993.

10. Filgueira, M.; Pinatti, D.G. In situ Diamond Wires - Part II: The Bronze 4 Weight \% Diamond Composite Cutting Rope. Journal of Material Processing Technology. In Press. 11. Anual Book of ASTM Standards. Section 3-Metals Testing Methods and Analytical Procedures v. 3, n. 1, 1985.

12. Diamond Wear. in Diamond in industry. Stone. ed. De Beers, p. 40-43, 1995. 